\title{
The role of practice: Object of analysis, permanent burden or source of inspiration?
}

\author{
Thomas W. Guenther ${ }^{1}$
}

Published online: 7 November 2016

(C) Springer-Verlag Berlin Heidelberg 2016

As scholarly researchers we are blessed with the possibility to think, to reflect and to create new ideas. In conversations with colleagues, Ph.D. and graduate students, the role of practice is often discussed. Some scholars like to maintain the ivory tower of research because practice seems to be complex, not sufficiently organized, constantly changing and chaotic. Others consider practice as a source for new ideas, for new opportunities to research and of reflecting what research can contribute to improve decision-making or management control, or in a wider sense to make "this world a better place".

We can observe scholars that like to keep in distance with practioners, joint round tables or practioners' institutions. Others are engaged in consulting, give talks or seminars to practioners or organize practice oriented associations or conferences. Of course, it is more than human that we find mutual prejudices: "colleague $\mathrm{x}$ is not a good researcher because he earns too much money in consulting or in seminars." "Researcher y can only live in his ivory tower, because contact with practice would challenge his models and assumptions.". We all have heard and noticed harsher comments by both parties, but I do not like to reflect those in this editorial.

After all, we should ask ourselves what the role of practice should be, especially for management control research, and how we can harmonize practice, research and teaching. From my point of view, there can be many answers, many ways and different views in coexistence. Today, I just want to inspire some thoughts by questions, not with the aim to deliver finished answers:

- Are we willing to reflect ourselves, our teaching and our research at all?

- How do we see ourselves as academic scholars?

\footnotetext{
$\bowtie$ Thomas W. Guenther

thomas.guenther@tu-dresden.de

1 Journal of Management Control, Technische Universität Dresden, 01062 Dresden, Germany
} 
- Are we interested in contacts with practice to challenge our way of thinking?

- Is practice interested in contact with us to challenge its ways of doing business?

- How do we consider practice in academic carreer pathes of Ph.D. students and professors?

- Are we able to translate results of rigorous research to understandable practice talk?

- Or the other way round, do we speak the language of practice to grasp their problems and thinking?

- How much of our time are we willing to invest in contacts and communication with practice?

- Do our performance measurement systems in higher education institutions consider practice and if yes, how?

- To what extent are journals interested in results for practice and in transmission of research results to practice? Etc.

This list could be much longer and it is not my personal list, but these are questions other colleagues and $\mathrm{Ph} . \mathrm{D}$. students typically ask in private conversations. Please consider these questions as a starting point to reflect what we are doing and where we should go for in the future.

As in the previous years, also for 2015 editors of JoMaC would like to honour the long lasting commitment of our reviewers, their support for the authors to further develop their papers and their art to motivate authors to get most out of their research with the JoMaC Best Reviewer Award 2015. Out of a long list of outstanding reviewers the editors finally decided to honour the following scholars:

Best reviewer award 2015: $\quad$ Lukas Goretzki, University of Innsbruck, Austria Runners up are:

Thorsten Knauer, Ruhr-University of Bochum, Germany

Paola Madini, Essade, Barcelona, Spain

Martina Linnenluecke, UQ Business School,

Melbourne, Australia

The editors of JoMaC are thankful for the great, continuous and enduring support and the time all reviewers dedicated to our journal. Without their support the Journal of Management Control could not exist.

For 2017 two special issues on interesting topics will be published:

Management Control in Family Firms, guest-edited by Martin Hiebl, University of Siegen, Germany; Martin Quinn, Dublin City University, Ireland; Justin Craig, Northwestern University, USA and Ken Moores, Bond University, Australia (Deadline: January 31, 2017).

Social and Ethical Issues in Management Accounting and Control, guest-edited by Philipp Schreck, Martin-Luther-Universität, Halle-Wittenberg, Germany; Frank Hartmann, Erasmus University Rotterdam, The Netherlands and Jan Endrikat, Technische Universität Dresden, Germany (Deadline: November 30, 2016).

Submissions to both special issues are welcome. The guest editors and editors are more than happy to give guidance and further support. 
The articles in this fourth issue of 2016 span a wide range of different methods and topics of management control research and, thus, show the richness and multitude of management accounting and control. Erkki K. Laitinen, Aapo Länsiluoto and Soila Salonen investigate based on a web-based survey of 132 Finnish firms how the frequency of budget preparation and the interactive use of budgets are associated with product innovation and firm performance.

The design and use of management control systems in education has got so far only limited attention in scholarly research. The study of Liv Bente Hannevik Friestad aims to narrow this knowledge gap by exploring the design and use of MCSs in schools and by local school authorities and the relationships with student performance. The paper uses a case study approach based on interviews with headmasters of schools and local authorities and on the study of additional materials.

Real options are often connected with long-term decision making for investments in non-financial markets. However, option-like situations also frequently encounter operating decisions. For optimal long-term decision support, short-term decision rules must consider the value of these options. Nils Crasselt and Christian Lohmann show based on simulation analysis how a fully rational decision rule that takes the longterm consequences of short-term decisions into account can be derived within the real options framework.

Finally, the recent management literature has increasingly investigated organizational ambidexterity, i.e., the ability to balance exploitative and explorative activities of a firm, as an important antecedent to firm survival and performance. Stefanie Gschwantner and Martin R. W. Hiebl examine in a short survey paper the current literature on organizational ambidexterity and management control systems. Overall, the results of their review show that rather a single specific management control system, but a package of management control systems and various forms of using such systems may be necessary to successfully achieve and manage organizational ambidexterity.

Dresden, November 2016

Prof. Dr. Thomas W. Günther

Managing editor 